\title{
Effect of Nanoadditives with Surfactant on the Surface Characteristics of Electroless Nickel Coating on Magnesium-Based Composites Reinforced with MWCNT
}

\author{
Ranganathan Dhinakaran, Rasu Elansezhian, and Arunachalam Arumugam Lalitha \\ Department of Mechanical Engineering, Pondicherry Engineering College, Pondicherry 605014, India \\ Correspondence should be addressed to Rasu Elansezhian; elansezhianr@pec.edu
}

Received 6 June 2013; Revised 23 October 2013; Accepted 20 November 2013

Academic Editor: S. Aravindan

Copyright (C) 2013 Ranganathan Dhinakaran et al. This is an open access article distributed under the Creative Commons Attribution License, which permits unrestricted use, distribution, and reproduction in any medium, provided the original work is properly cited.

\begin{abstract}
An experimental investigation has been carried out on optimizing process parameters of electroless nickel-phosphorous coatings on magnesium composite reinforced with carbon nanotube. A comprehensive experimental study of electroless Ni-P coatings on magnesium composite reinforced with multiwalled carbon nanotube under specific coating conditions was performed. The electroless coating bath consists of nickel sulphate $(26 \mathrm{~g} / \mathrm{L})$, sodium hypo-phosphite $(30 \mathrm{~g} / \mathrm{L})$ as reducing agent, sodium acetate $(16 \mathrm{~g} / \mathrm{L})$ as stabilizer, and ammonium hydrogen difluoride $(8 \mathrm{~g} / \mathrm{L})$ as the complexing agent. The surfactant SLS was added in the solution for better wetting and spreading of coating on substrate. The stabilizer thiourea (1 ppm) was added in the bath to prevent decomposition of bath. Different nanoadditives such as $\mathrm{ZnO}, \mathrm{Al}_{2} \mathrm{O}_{3}$, SiO with various concentrations were used in the bath and their influence on coating process characteristics were studied The nano additives such as $\mathrm{ZnO}, \mathrm{Al}_{2} \mathrm{O}_{3}$, $\mathrm{SiO}$ were added at concentrations of $0.1 \%, 0.5 \%, 1 \%$, and $2 \%$ in the EN bath. The output parameters such as surface roughness, microhardness, specific wear rate, and surface morphology were measured. Surface morphology was studied using scanning electron microscope. The results showed that the proposed method resulted in significant improvement on the quality of the coatings produced.
\end{abstract}

\section{Introduction}

Electroless nickel coating has received widespread acceptance as it provides a uniform deposit on irregular surfaces, direct deposition on surface-activated nonconductors, formation of less porous deposits, and high hardness and excellent resistance to wear, abrasion, and corrosion $[1,2]$. All smooth surfaces possess some degree of roughness, even if only at the atomic level. Correct function of the fabricated component often is critically dependent on its degree of roughness. Every machining operation bequeaths some characteristic on the machined surface. This characteristic microirregularities left by the cutting tool are termed as surface irregularity or surface roughness [3]. Roughness is sometimes an undesirable property, as it may cause friction, wear, drag, and fatigue, but it is sometimes beneficial, as it allows surfaces to trap lubricants and prevents them from welding together. Magnesium composites have promising properties for several industrial applications because of their low density [4]. Magnesium composite with metallic (electroless/electroplating) deposits are being used, in new light-weight engines which are less in weight and hence consume less energy. However, metallic coatings in magnesium are having multitudinous problems caused by surface roughness. Example of mechanical malfunction can be found in high-performance engine machine parts which are required to move or rotate at high speed without wear. Excess surface roughness can lead to unacceptably high levels of frictional heating, causing damage and even failure [5]. Surfactants are specifically added into the electrolyte bath to reduce the vertical component of surface tension forces, which binds the nickel particles to the hydrogen gas bubbles generated during the plating reaction. Due to this, uniform and pit-free coating can be obtained. Smooth and pit-free electroless $\mathrm{Ni}-\mathrm{P}$ deposits were obtained by adding $150 \mathrm{ppm}$ of sodium dodecyl sulfate (SDS) to the electroless nickel bath [5]. Similarly, a very brief conclusion was derived by Hagiwara et al. [6] as well, who studied the effect of three different surfactants added in the $\mathrm{Ni}-\mathrm{P}$ electroless bath on the 
morphology of the resulting Ni-P particles. Many attempts have been made to find out the effect of surfactants on the roughness of electrodeposited Ni-P coatings. Tripathy et al. [7] and Wheeler et al. [8] studied a numerical model to explain the influence of catalytic surfactant on roughness evaluation. Alsari et al.'s [9] research studied the SDS effect on the electroplating deposition. Several researchers had carried out investigations on the influence of surfactants on coatings of ferrous substrate [10-12]. Elansezhian et al. [13] investigated the influence of SDS on quality of electroless $\mathrm{Ni}-$ $P$ coatings and reported that there is a possibility of significant improvement in the average surface finish of electroless $\mathrm{Ni}-\mathrm{P}$ deposit on mild steel. However, there was no such investigation on magnesium composite with coating of nanoadditives and moreover it is complicated because of the corrosive nature of magnesium substrate in the electrolyte bath. Hence, in this investigation, three types of nanoadditives such as $\mathrm{Al}_{2} \mathrm{O}_{3}, \mathrm{SiO}$, and $\mathrm{ZnO}$ were used in the electrolyte bath and their influence on electroless Ni-P deposit of magnesium composite was studied. The quality of obtaining electroless $\mathrm{Ni}-\mathrm{P}$ deposit on the substrate depends on many factors such as temperature, $\mathrm{pH}$ of bath, bath loading, concentrations of nickel and the reducing agent, and the surface properties of the substrates [14-16]. Wetting agents, such as ionic and nonionic surfactants, are often added to increase the wettability of coated surfaces [17]. Despite the complicated behaviour of the deposition reactions, qualitative discussions on the effects of added nanoadditivesss such as $\mathrm{Al}_{2} \mathrm{O}_{3}, \mathrm{SiO}$, and $\mathrm{ZnO}$ in the presence of surfactant (SLS) the surface roughness, surface morphology, microhardness, specific wear rate, and wear morphology are investigated and reported in this paper.

\section{Experimental Details}

The substrate material used in the present study was magnesium composite synthesised with MWCNT. The specimen size was $26 \times 8 \times 7 \mathrm{~mm}$. The magnesium composite was indigenously synthesised by using magnesium stir casting furnace. The output of casting was in rod form. The rod was cut into the desired shape by using wire cut EDM process. The $\%$ of elements present in magnesium composite was presented in Table 1 and the composition was confirmed with EDX. The bath composition and all the operation parameters for the electroless $\mathrm{Ni}-\mathrm{P}$ deposit with chromiumfree pretreatment are reported in Table 2. In addition, anionic surface activator sodium lauryl sulphate (SLS) was used in this study as a surface activator and to enhance the properties of the deposits. No agitation was employed to the bath during the plating process. At critical micelle concentration (CMC) concentration, surface activator reduces the contact angle and this leads to the better wettability of Ni-P deposit. The SLS surfactant was used at its CMC value $1.2 \mathrm{~g} / \mathrm{L}$ concentration. The samples were given thick nickel strike for about 20 minutes by using electroless bath itself and without any activator and then dipped into the bath having surface activator. The sizes of nanoparticles used in bath were $\mathrm{ZnO}(50 \mathrm{~nm}), \mathrm{Al}_{2} \mathrm{O}_{3}(40 \mathrm{~nm})$ and $\mathrm{SiO}(25 \mathrm{~nm})$, and all the nanopowders were imported from Alfa Aesar, USA, with a purity of $99.9 \%$. After coatings all the samples were
TABLE 1: Percentage of elements present in magnesium composite.

\begin{tabular}{lc}
\hline Elements & $\%$ \\
\hline Magnesium & 90 \\
Aluminium & 8 \\
Zinc & 1 \\
CNT & 1 \\
\hline
\end{tabular}

TABLE 2: Compositions of coating bath for electroless Ni-P used in the experiments.

\begin{tabular}{lccc}
\hline Particulars & \multicolumn{3}{c}{ Quantity (g/L) } \\
& Bath A & Bath B & Bath C \\
\hline $\mathrm{NiSo}_{4} \cdot 6 \mathrm{H}_{2} \mathrm{O}$ & 26 & 26 & 26 \\
$\mathrm{NaH}_{2} \mathrm{Po}_{2} \cdot \mathrm{H}_{2} \mathrm{O}$ & 30 & 30 & 30 \\
$\mathrm{HF}(40 \%, \mathrm{v} / \mathrm{v})$ & $12 \mathrm{~mL}$ & $12 \mathrm{~mL}$ & $12 \mathrm{~mL}$ \\
$\mathrm{NaC}_{2} \mathrm{H}_{3} \mathrm{O}_{2}$ & 16 & 16 & 16 \\
$\mathrm{NH}_{4} \mathrm{HF}_{2}$ & 8 & 8 & 8 \\
$\mathrm{NaC}_{12} \mathrm{H}_{25} \mathrm{So}_{4}$ & 1.2 & 1.2 & 1.2 \\
$\mathrm{Thiourea}_{\mathrm{Nano}-\mathrm{Al}_{2} \mathrm{O}_{3} 40 \mathrm{~nm}}$ & $0.5-2$ & $1 \mathrm{ppm}$ & $1 \mathrm{ppm}$ \\
Nano- $\mathrm{ZnO}(50 \mathrm{~nm})$ & - & - & - \\
Nano-SiO $(25 \mathrm{~nm})$ & - & $0.5-2$ & - \\
\hline
\end{tabular}

cleaned with deionized water for 2 minutes and dried. Wear studies were performed on a Ducom pin-on-disc model TR201 friction and wear monitor with a computer interfaced data acquisition system. For all tests, sliding velocity was fixed at $0.5 \mathrm{~m} / \mathrm{s}$ and sliding distance was $1000 \mathrm{~m}$. The load applied was $30 \mathrm{~N}$. No lubrication was done during the test. (Linear variable differential transformer) LVDT was used to measure the linear displacement of the specimen and a load cell was used to measure the frictional force experienced by the specimen under load. The pins were coated with electroless Ni-P deposits with and without surfactant. The disc selected for wear test was high carbon-high chromium steel, fully hardened to $65 \mathrm{HRC}$ and finished to $0.2 R_{a}$. All the experiments were conducted in an air-conditioned room at $20^{\circ} \mathrm{C}$. Wear tracks on the electroless coated pins were examined using a scanning electron microscope (SEM).

The magnesium samples prepared for EN-coatings are shown in Figure 1. The experimental setup used for ENcoating is shown in Figure 2. The EN bath prepared for the coating is presented in Figure 3. The coated samples are presented in Figure 4. Microhardness of the EN deposits was estimated using a Future-Tech microhardness tester with a diamond pyramid as an indenter, $200 \mathrm{gm}$ load, and 15 seconds loading time. Surface roughness of EN deposits was measured using a stylus instrument.

\section{Results and Discussion}

3.1. Surface Morphology of Nanoadditivesss with and without Surfactant in Electroless Ni-P Deposits on Magnesium. The SEM micrographs of EN-coated samples with nanoadditivesss are shown in Figures 6, 7, and 8. Without nanoadditivesss, the surface of the coating consists of relatively lower 


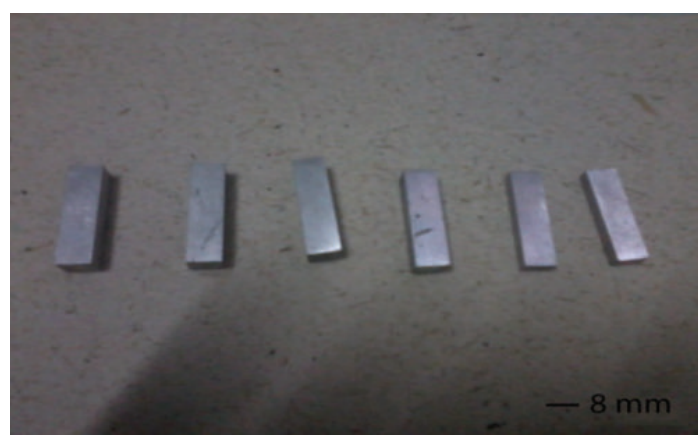

FIgURE 1: Prepared samples for EN-coatings.

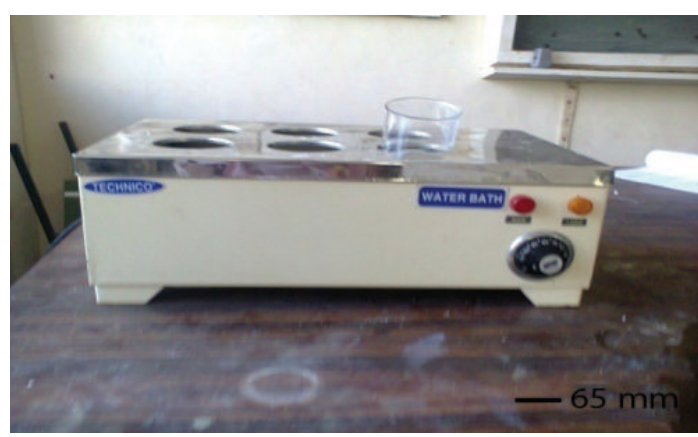

FIGURE 2: Experimental setup used for EN-coatings.

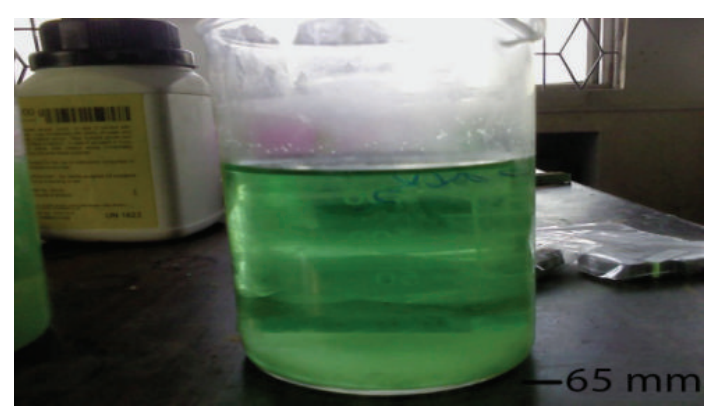

Figure 3: Prepared EN bath.

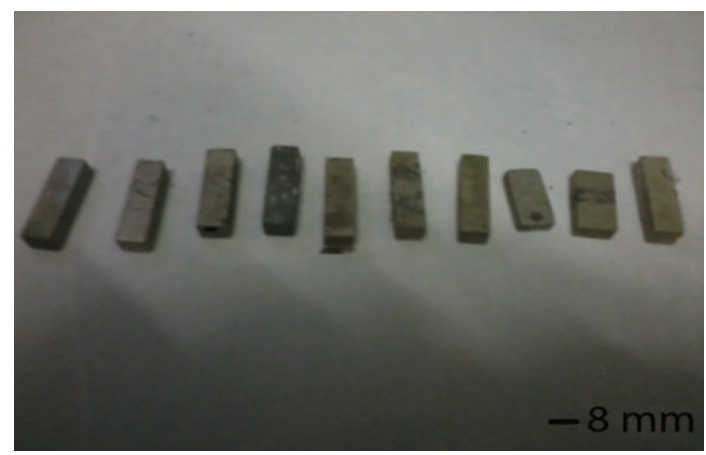

FIGURE 4: EN-coated samples.

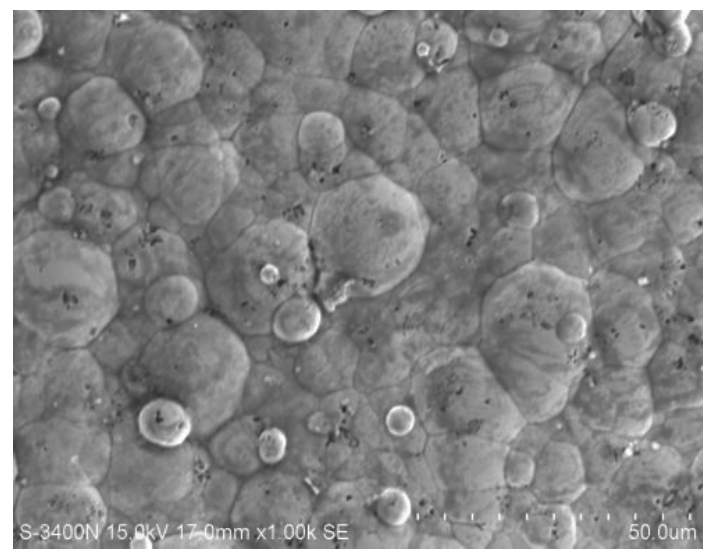

FIGURE 5: SEM micrograph $(1000 \times)$ of electroless $\mathrm{Ni}-\mathrm{P}$ coated on magnesium $(\mathrm{Mg})$ composite reinforced with multiwall carbon nanotube (MWCNT) without surfactant and nanoadditivesss.

amount of nickel particles on the matrix and nonuniform deposition of nickel resulted in higher surface roughness. The SEM micrograph presented in Figure 5 clearly showed the nonuniform deposition of nickel particles on the surface of substrate.

\subsubsection{Variation of $\mathrm{Al}_{2} \mathrm{O}_{3}$. See Figure 6.}

\subsubsection{Variation of $\mathrm{SiO}$. See Figure 7.}

\subsubsection{Variation of $\mathrm{ZnO}$. See Figure 8.}

After adding nanoadditivesss with surfactant, the surface morphology has changed from nonsmooth nodular appearance to a smooth surface resulting lower surface finish values. This similar trend was obtained by the earlier researcher's findings $[18,19]$. The reason is that the amount of nickel particles deposited on the substrate surface is enhanced. This is due to the fact that the surfactant reduces the contact angle and this leads to the better wettability of $\mathrm{Ni}-\mathrm{P}$ deposit on the substrate.

On the EN-coated substrate surface, the traces of nano$\mathrm{Al}_{2} \mathrm{O}_{3}$, nano-SiO and nano- $\mathrm{ZnO}$ particles are clearly seen over the Ni-P matrix and the nanoadditivesss are confirmed with EDX (see Figures 21-26). Among the three nanoadditivesss, addition of nano-SiO resulted in smooth surface finish and the surface finish is in the order of $0.26 \mu \mathrm{m}$ as compared to tha of nano- $\mathrm{Al}_{2} \mathrm{O}_{3}(0.58 \mu \mathrm{m})$ and $\mathrm{ZnO}(1.27 \mu \mathrm{m})$.

3.2. Surface Roughness of Nanoadditivesss with Surfactant in Electroless Ni-P Deposits on Magnesium Composite. The variation of average surface roughness value $\left(R_{a}\right)$ of the coated layer with $\mathrm{Al}_{2} \mathrm{O}_{3}, \mathrm{SiO}$, and $\mathrm{ZnO}$ are shown in Figures 9,10 , and 11 . At low $\%$ of nanoadditives, the surface roughness value is high; when there is increase in $\%$ of nanoadditivesss the average roughness value is low at $2 \%$. The nanoadditivess $\mathrm{SiO}$ gives the better surface $0.26 R_{a}$ at $2 \%$ followed by $\mathrm{Al}_{2} \mathrm{O}_{3}$ $\left(0.58 R_{a}\right)$ and $\mathrm{ZnO}\left(1.27 R_{a}\right)$. The average surface roughness value remains low at $2 \%$ concentration of all nanoadditivesss. Further increase in the concentration of nanoadditivesss does 


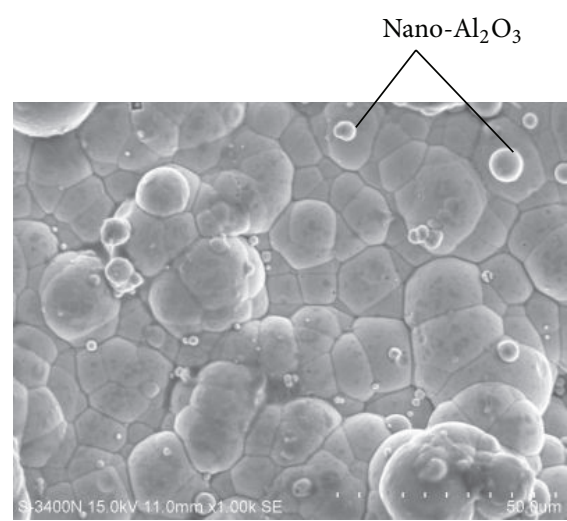

(a)

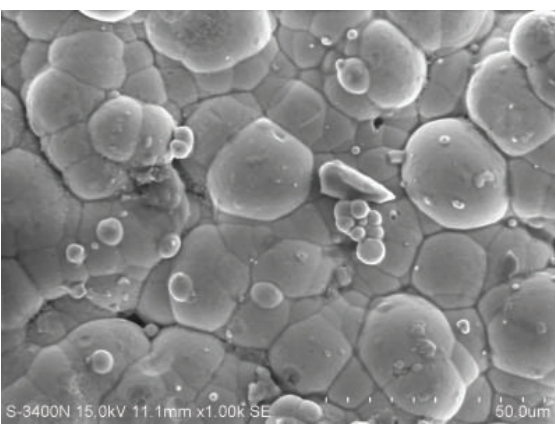

(c)

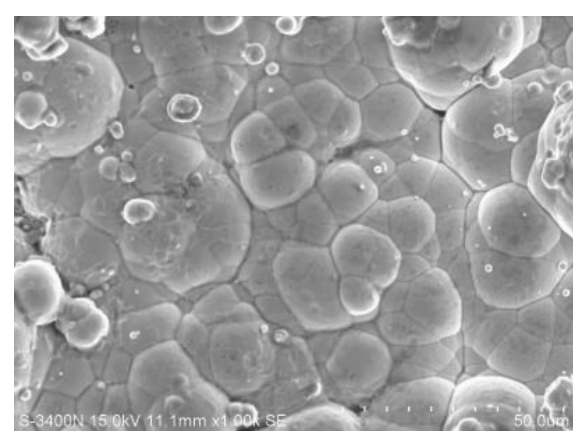

(b)

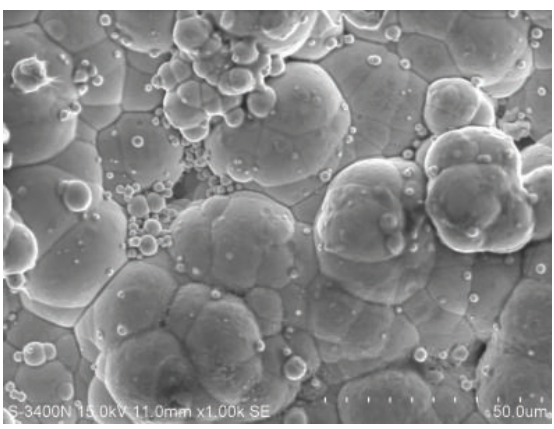

(d)

FIGURE 6: SEM micrograph $(1000 \times)$ of electroless Ni-P coated with SLS surfactant on magnesium $(\mathrm{Mg})$ composite reinforced with multiwall carbon nanotube (MWCNT) at various $\mathrm{Al}_{2} \mathrm{O}_{3}$ concentrations: (a) $0.1 \%$, (b) $0.5 \%$, (c) $1 \%$, and (d) $2 \%$.

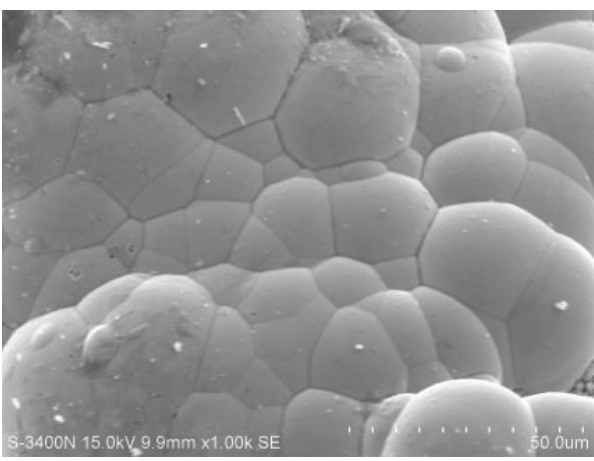

(a)

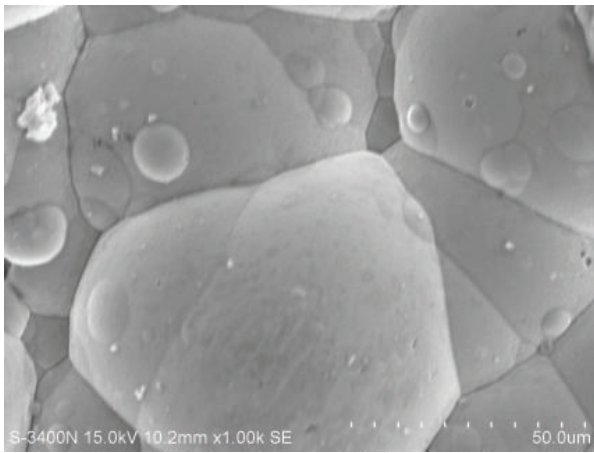

(c)

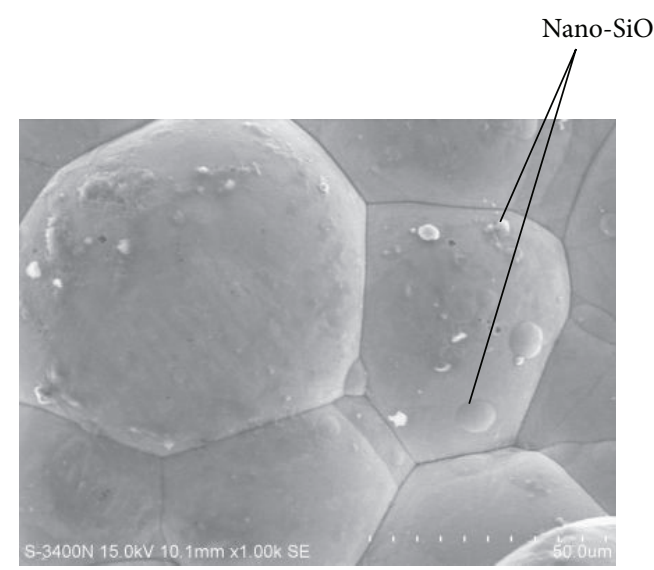

(b)

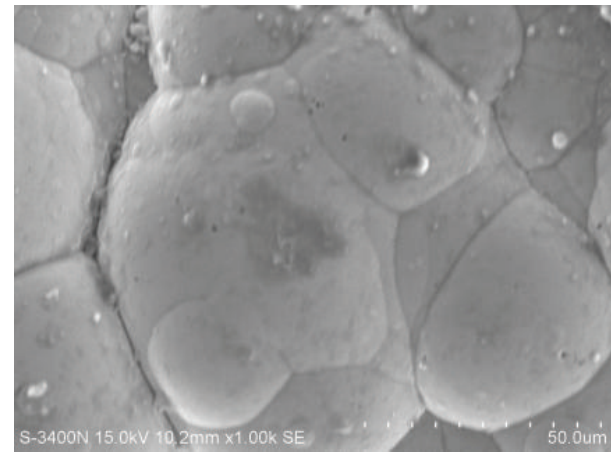

(d)

FIGURE 7: SEM micrograph $(1000 \times)$ of electroless Ni-P coated with SLS surfactant on magnesium $(\mathrm{Mg})$ composite reinforced with multiwall carbon nanotube (MWCNT) at various $\mathrm{SiO}$ concentrations: (a) $0.1 \%$, (b) $0.5 \%$, (c) $1 \%$, and (d) $2 \%$. 


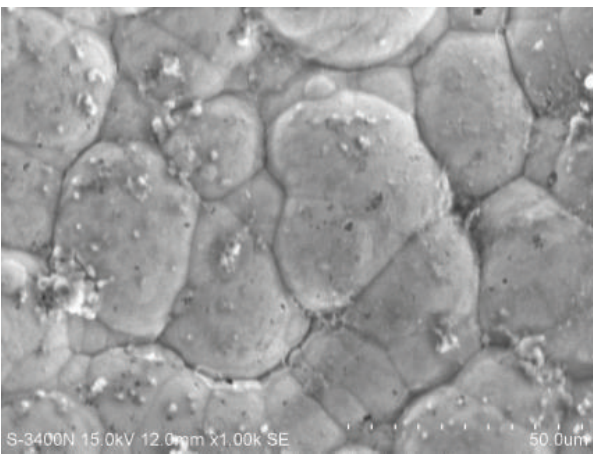

(a)

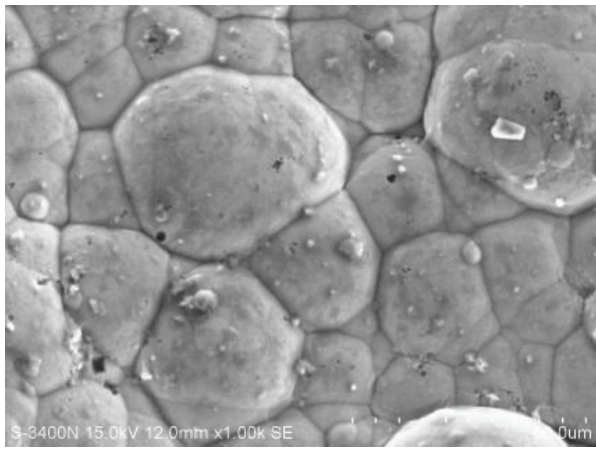

(c)

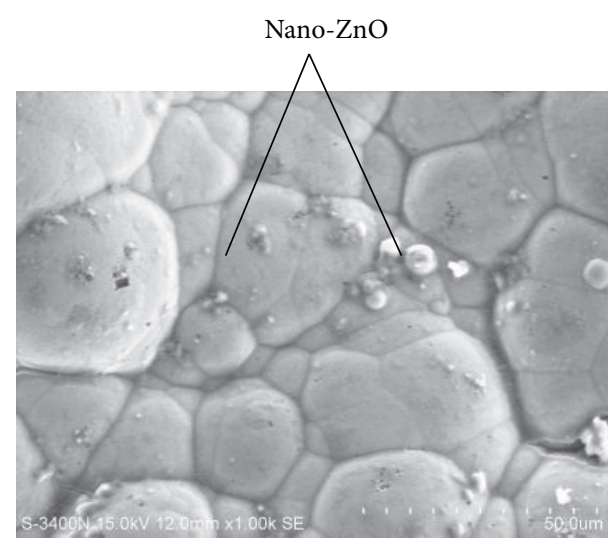

(b)

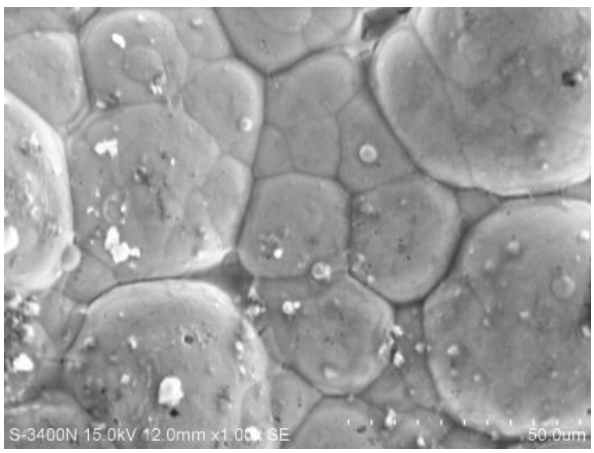

(d)

FIGURE 8: SEM micrograph (1000×) of electroless Ni-P coated with SLS surfactant on magnesium (Mg) composite reinforced with multiwall carbon nanotube (MWCNT) at various $\mathrm{ZnO}$ concentrations: (a) $0.1 \%$, (b) $0.5 \%$, (c) $1 \%$, and (d) $2 \%$.

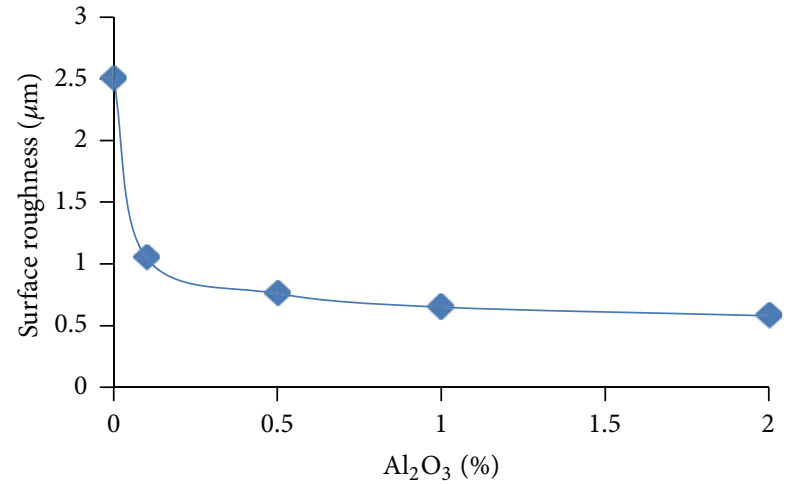

FIGURE 9: Variation in average surface roughness of EN-coatings as a function of $\mathrm{Al}_{2} \mathrm{O}_{3}$ with surfactant (SLS) concentration in the EN bath.

not influence the surface roughness vales very much. Furthermore, agglomeration of nanoparticles takes place over the $\mathrm{ENi}-\mathrm{P}$ matrix and this leads to increased surface roughness.

3.3. Microhardness of Nanoadditivesss with Surfactant in Electroless Ni-P Deposits on Magnesium Composite. Figures 12, 13 , and 14 showed the variation of microhardness of ENcoating with respect to $\mathrm{Al}_{2} \mathrm{O}_{3}, \mathrm{SiO}$, and $\mathrm{ZnO}$. At low \% of nanoadditives the microhardness value is low; when there is

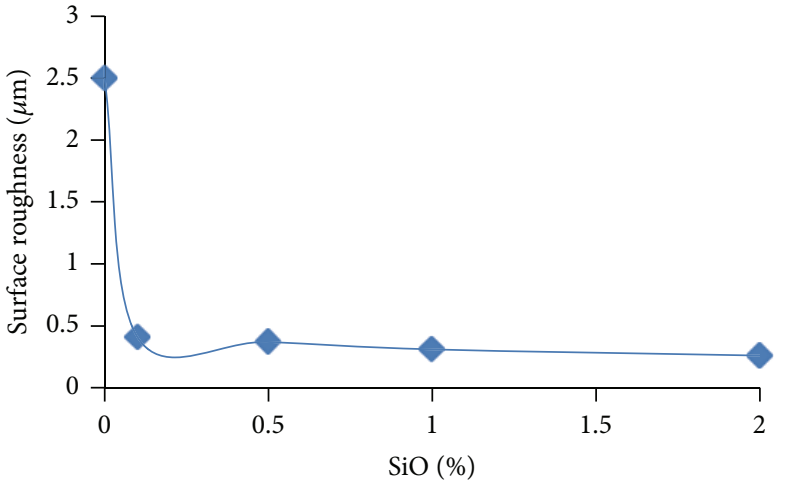

FIGURE 10: Variation in average surface roughness of EN-coatings as a function of $\mathrm{SiO}$ with surfactant (SLS) concentration in the EN bath.

increase in $\%$ of nanoadditivesss the microhardness value is high and it is maximum at $2 \%$ addition of nanoadditivesss. The nanoadditivess $\mathrm{SiO}$ shows the high hardness (980.2 $\left.\mathrm{VHN}_{200}\right)$ at $2 \%$ followed by $\mathrm{Al}_{2} \mathrm{O}_{3}\left(950.4 \mathrm{VHN}_{200}\right)$ and $\mathrm{ZnO}$ $\left(927.2 \mathrm{VHN}_{200}\right)$. The reason for increase in the microhardness values of $\mathrm{ENi}-\mathrm{P}$ coatings with nanoadditivesss in presence of surfactant may be due to uniform deposition of nanoparticles on the Ni-P matrix and filling the micro gaps of $\mathrm{Ni}-\mathrm{P}$ coated layer thus increasing the density of coated layer. Similar kind 


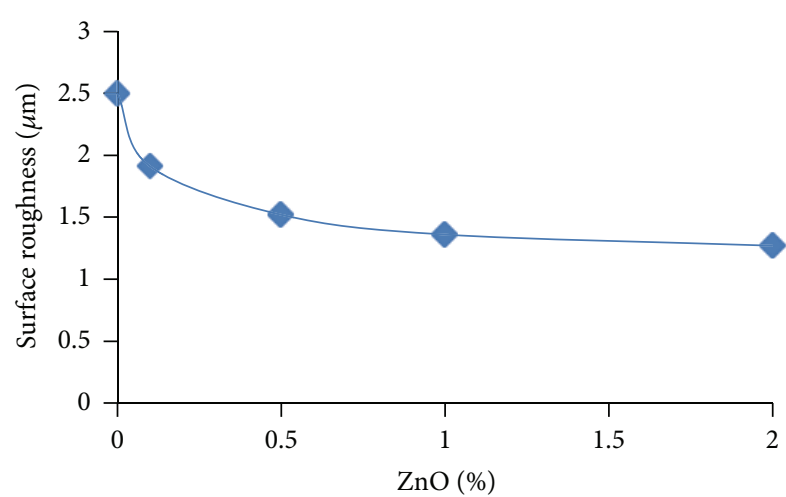

FIGURE 11: Variation in average surface roughness of EN-coatings as a function of $\mathrm{ZnO}$ with surfactant (SLS) concentration in the EN bath.

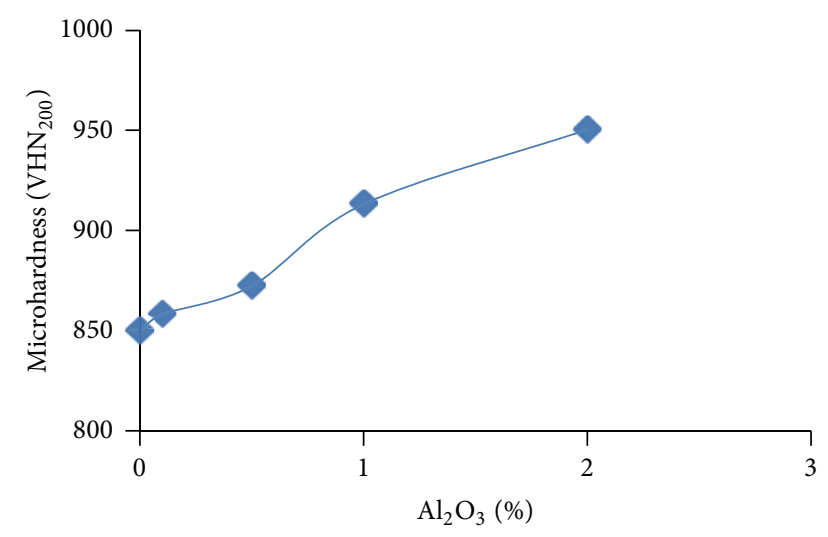

FIGURE 12: Variation in microhardness of EN-coatings as a function of $\mathrm{Al}_{2} \mathrm{O}_{3}$ with surfactant (SLS) in EN bath.

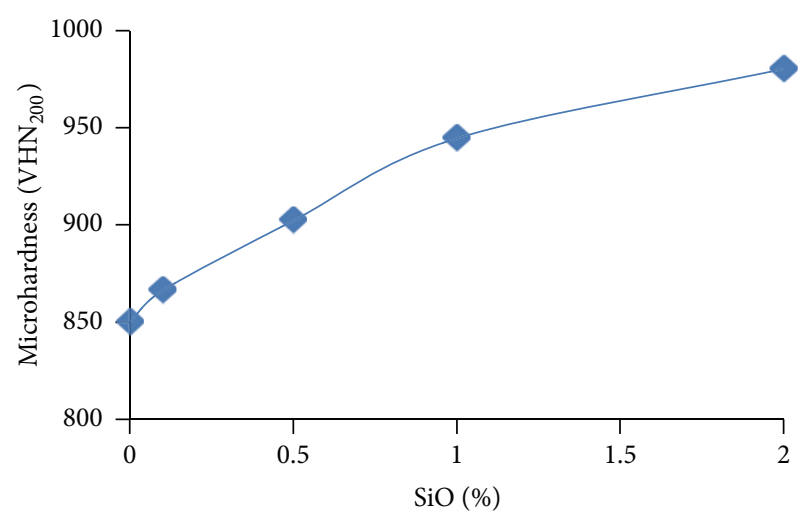

FIGURE 13: Variation in microhardness of EN-coatings as a function of $\mathrm{SiO}$ with surfactant (SLS) in EN bath.

of trend was obtained by earlier researchers after adding nanoadditivesss in their respective studies $[20,21]$.

3.4. Effect of Nanoadditivesss on Specific Wear Rate. The specific wear rate for electroless $\mathrm{Ni}-\mathrm{P}$ coatings for various nanoadditivesss $\mathrm{Al}_{2} \mathrm{O}_{3}$ and $\mathrm{SiO}$, are shown in Figures 15 and 16, respectively. It is clearly visible that with increased \% of

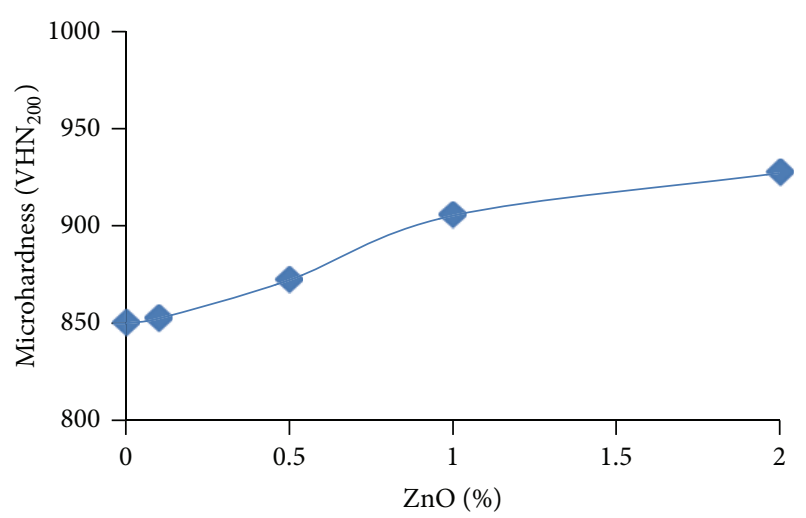

FIGURE 14: Variation in microhardness of EN-coatings as a function of $\mathrm{ZnO}$ with surfactant (SLS) in EN bath.

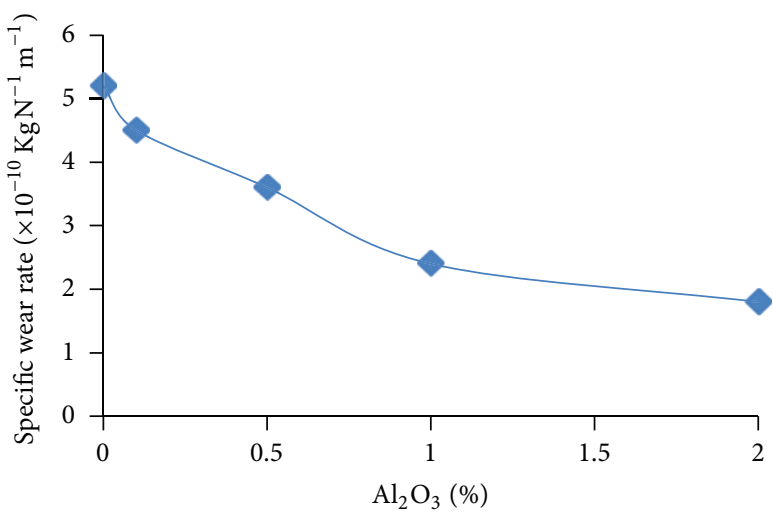

FIgURE 15: Variation in specific wear rate of EN-coatings as a function of $\mathrm{Al}_{2} \mathrm{O}_{3}$ with surfactant (SLS) in EN bath.

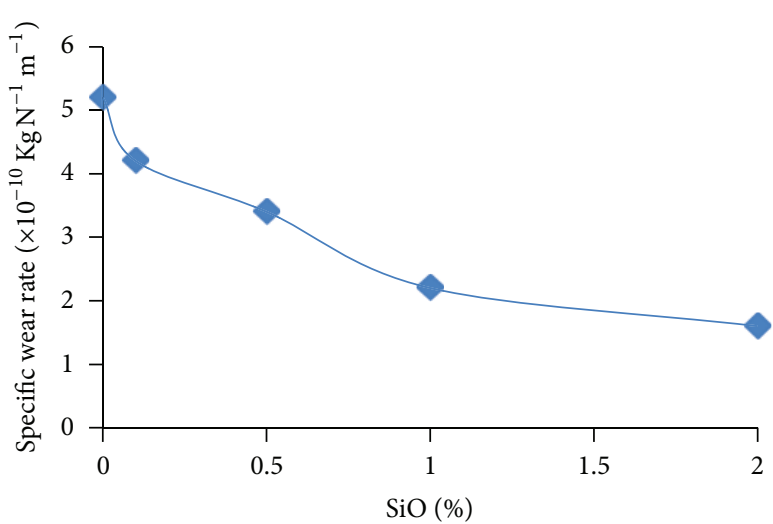

FIGURE 16: Variation in specific wear rate of EN-coatings as a function of $\mathrm{SiO}$ with surfactant (SLS) in EN bath.

nanoadditivesss, the EN-coatings show better wear resistance. Adhesive wear is characterized by the transfer of material from one surface to other which may later be removed as wear debris. The rate of adhesive wear is influenced by several factors such as hardness and adhesion between the interacting surfaces. Adhesive wear is related, though not directly to the hardness of the surface, which is an 


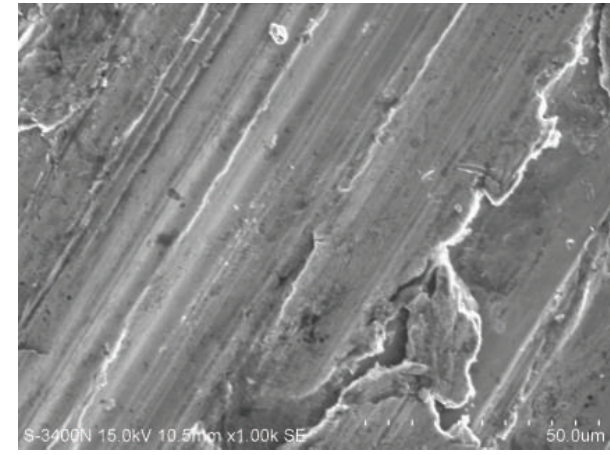

(a)

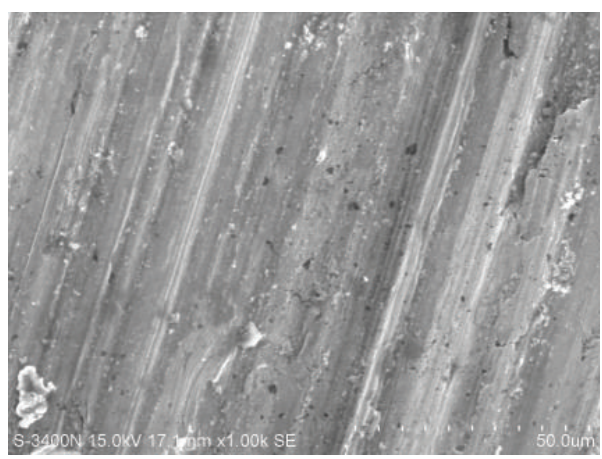

(c)

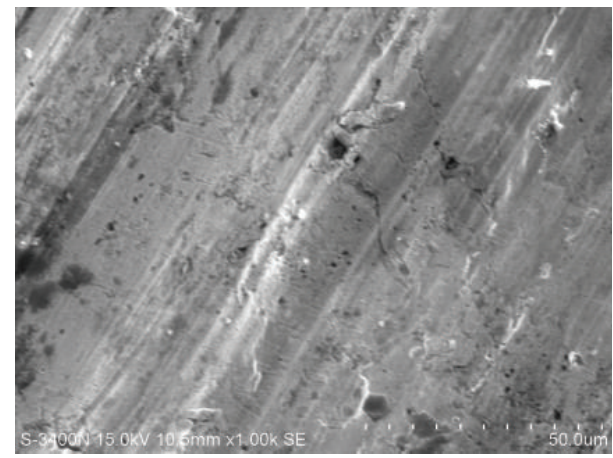

(b)

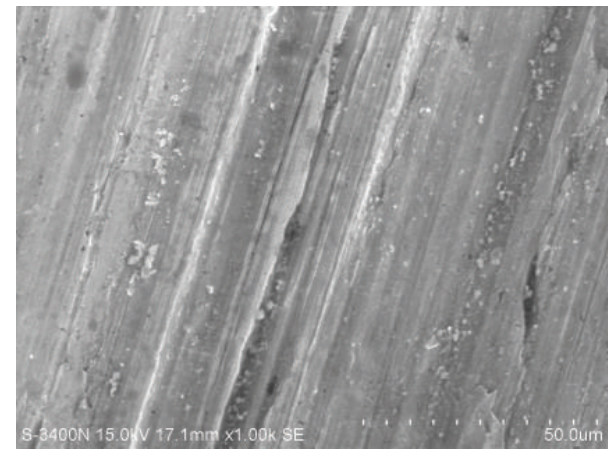

(d)

FIGURE 17: SEM micrograph $(1000 \times)$ of wear track for coated magnesium $(\mathrm{Mg})$ composite reinforced with multiwall carbon nanotube (MWCNT) at various $\mathrm{Al}_{2} \mathrm{O}_{3}$ (a) $0.1 \%$ (b) $0.5 \%$ (c) $1 \%$ (d) $2 \%$.

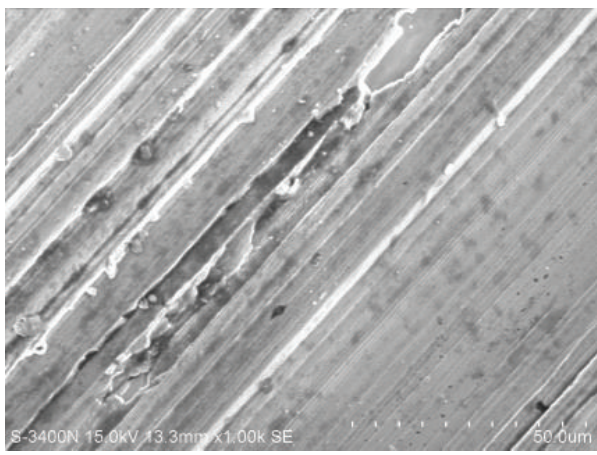

(a)

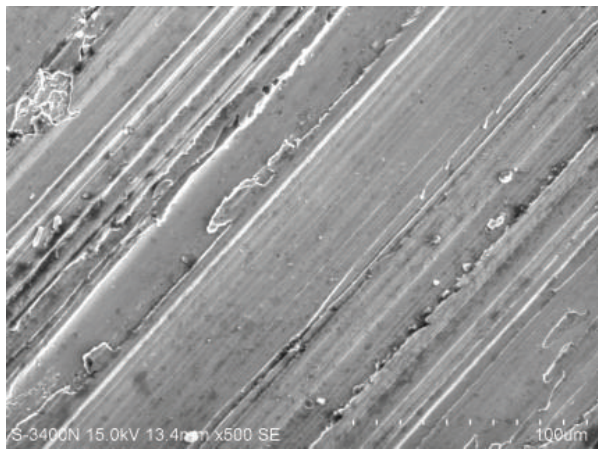

(c)

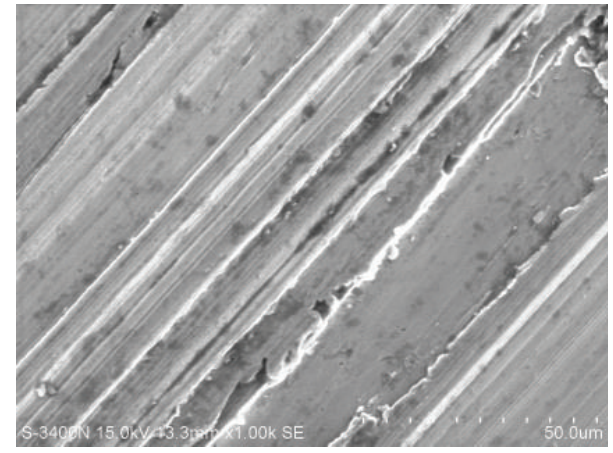

(b)

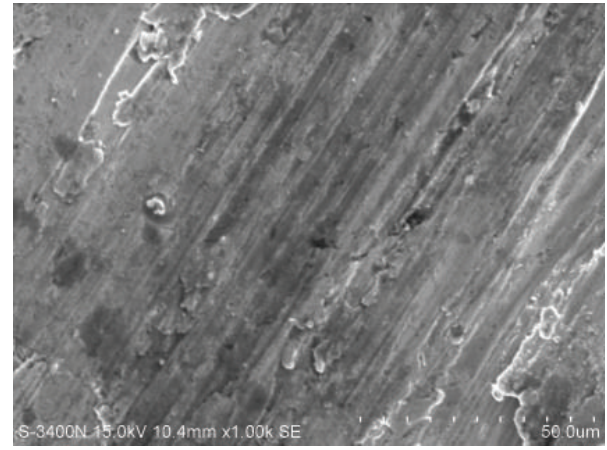

(d)

FIGURE 18: SEM micrograph $(1000 \times)$ of wear track for coated magnesium $(\mathrm{Mg})$ composite reinforced with multiwall carbon nanotube (MWCNT) at various $\mathrm{SiO}$ (a) $0.1 \%$ (b) $0.5 \%$ (c) $1 \%$ (d) $2 \%$. 


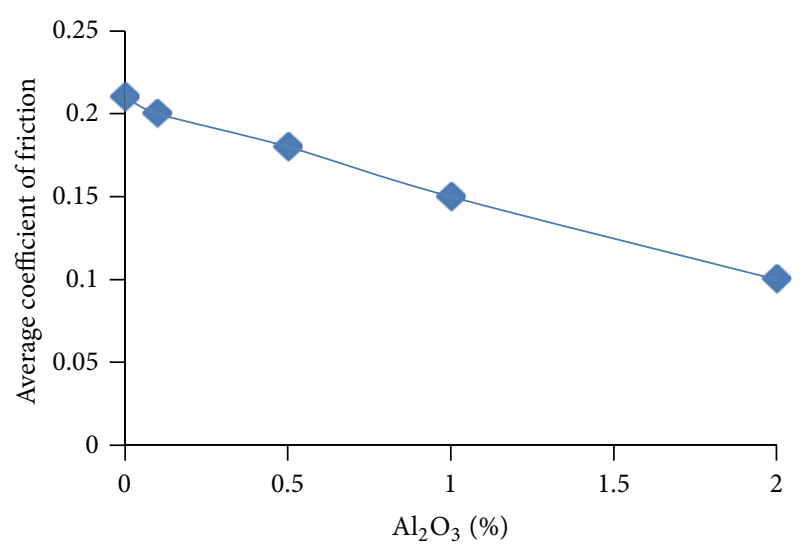

FIGURE 19: Variation in coefficient of friction of EN-coatings as a function of $\mathrm{Al}_{2} \mathrm{O}_{3}$ with surfactant (SLS) in EN bath.

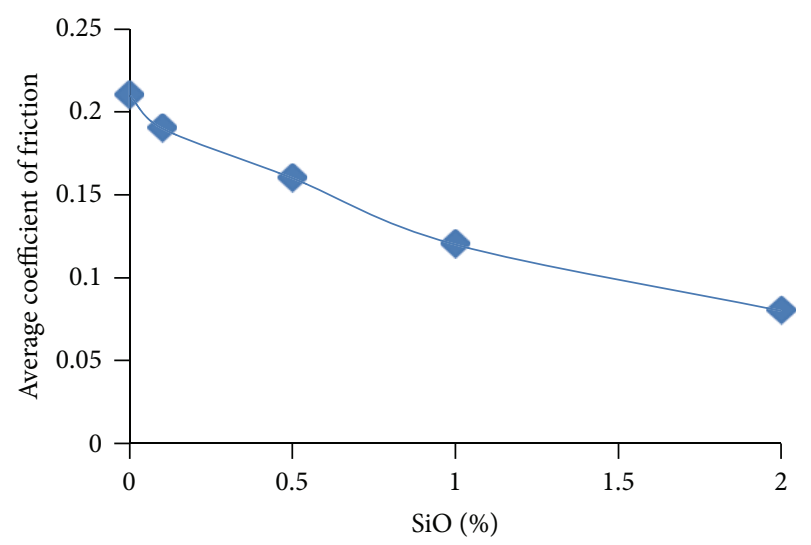

FIGURE 20: Variation in coefficient of friction of EN-coatings as a function of $\mathrm{SiO}$ with surfactant (SLS) in EN bath.

indication of how much the tops of the asperities deform plastically. Greater the hardness less is the deformation, and consequently, less intimate is the contact. This leads to lower friction. The corresponding graphical values are shown in Figures 19 and 20.

Wear morphology of coated samples with different \% of nanoadditivesss of nano $\mathrm{Al}_{2} \mathrm{O}_{3}$ and nano $\mathrm{SiO}$ are presented in Figures 17 and 18 . At lower concentrations (0.5\%) of nanoadditivesss, the delamination of coatings and their debris are clearly visible in the wear morphology (Figure 17(a)). As the $\%$ of nanoadditivesss increased the wear tracks are smooth and exhibited a low wear rate. The reason for the low wear rate at higher concentration of nanoadditivesss is increased hardness of coatings.

3.5. Effect of Nanoadditivesss on Coefficient of Friction. The electroless Ni-P coatings produced with addition of nanoadditivesss with SLS surfactant in the EN bath lowered the friction coefficient upto $52.38 \%$ and $61.90 \%$ with the addition of nano $\mathrm{Al}_{2} \mathrm{O}_{3}$ and nano $\mathrm{SiO}$ when compared to the coatings produced without nanoadditivesss. Due to increase in the hardness and the amorphous fraction in the coating the coefficient of friction was reduced. The smoother surface finish

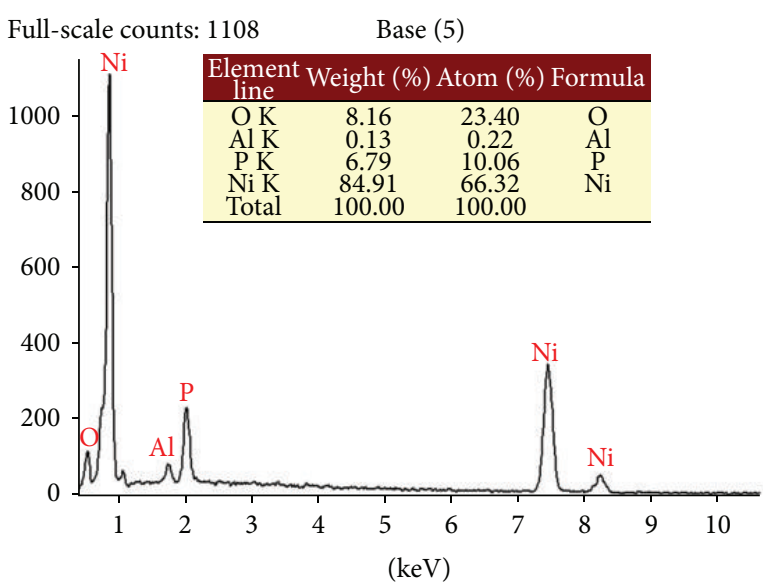

FIGURE 21: EDX diffractogram showing the \% of elements present on the EN-coated $\mathrm{Mg}$ sample with $0.5 \%$ nano- $\mathrm{Al}_{2} \mathrm{O}_{3}$.

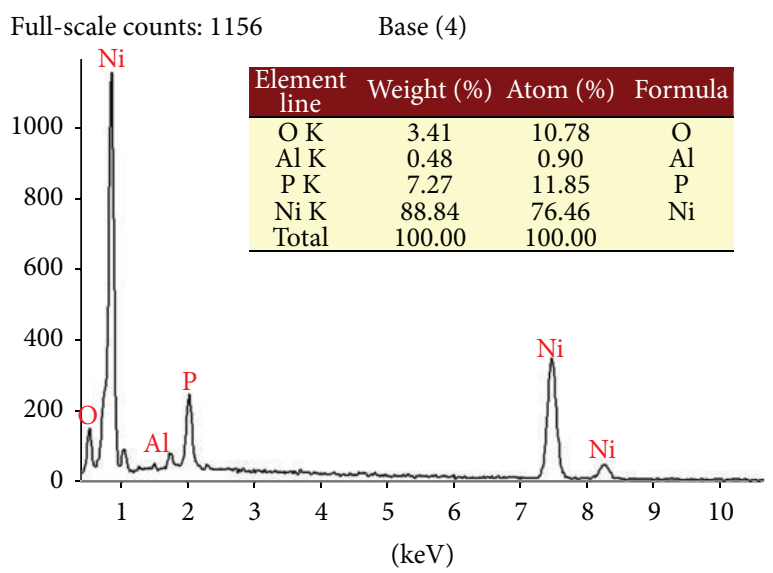

FIGURE 22: EDX diffractogram showing the \% of elements present on the EN-coated $\mathrm{Mg}$ sample with $2 \%$ nano- $\mathrm{Al}_{2} \mathrm{O}_{3}$.

Base (2)

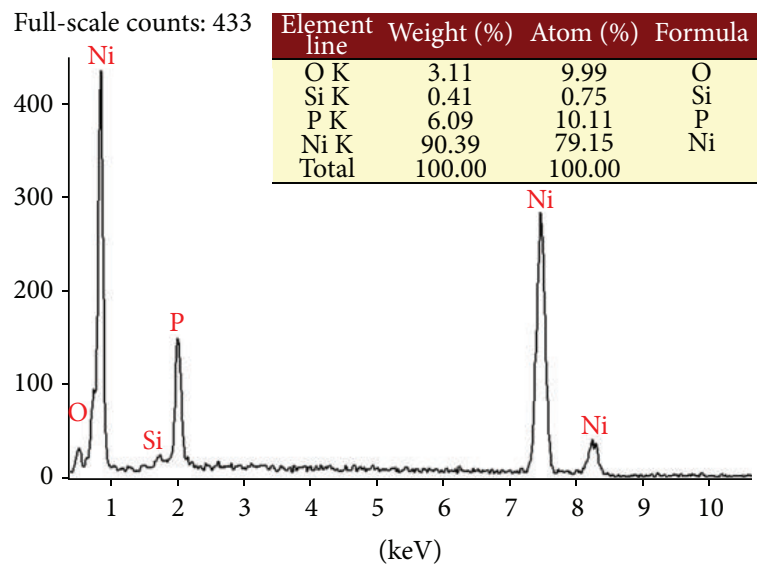

FIgURE 23: EDX diffractogram showing the \% of elements present on the EN-coated $\mathrm{Mg}$ sample with $0.5 \%$ nano-SiO. 


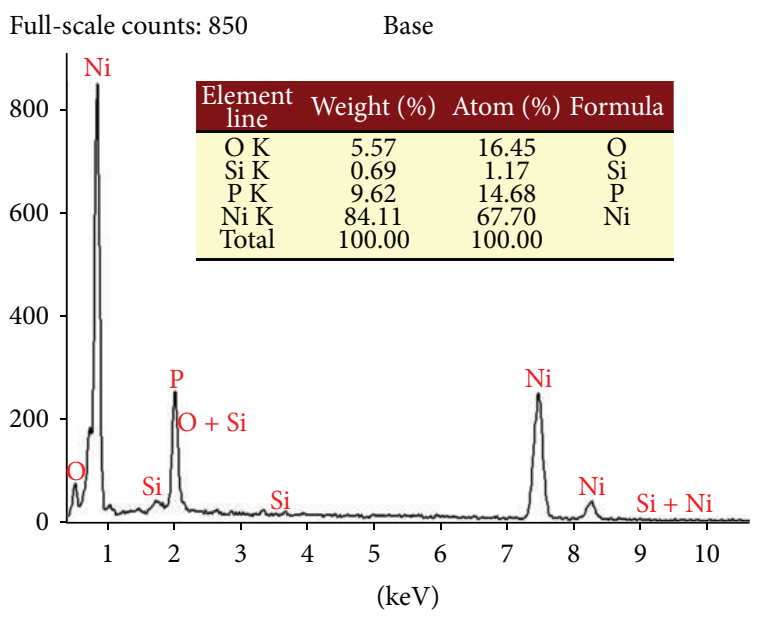

FIgURE 24: EDX diffractogram showing the \% of elements present on the EN-coated Mg sample with 2\% nano-SiO.

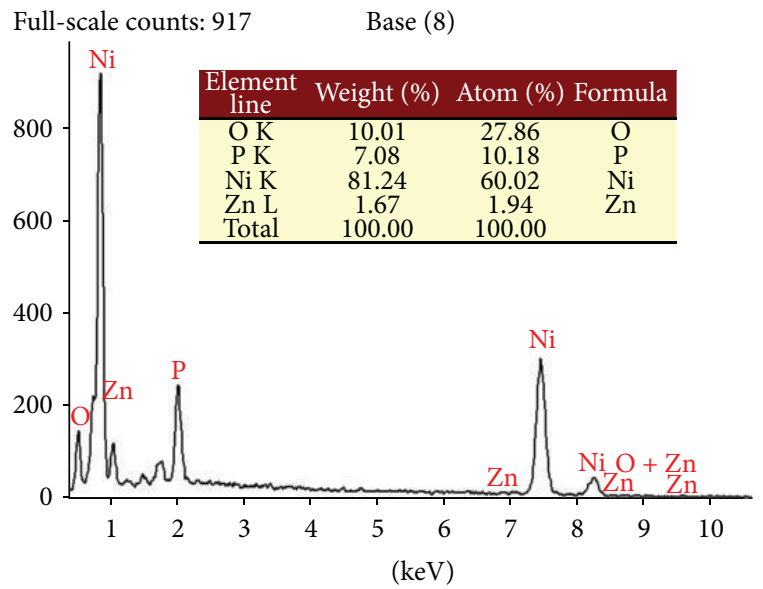

FIGURE 25: EDX diffractogram showing the \% of elements present on the EN-coated $\mathrm{Mg}$ sample with $0.5 \%$ nano- $\mathrm{ZnO}$.

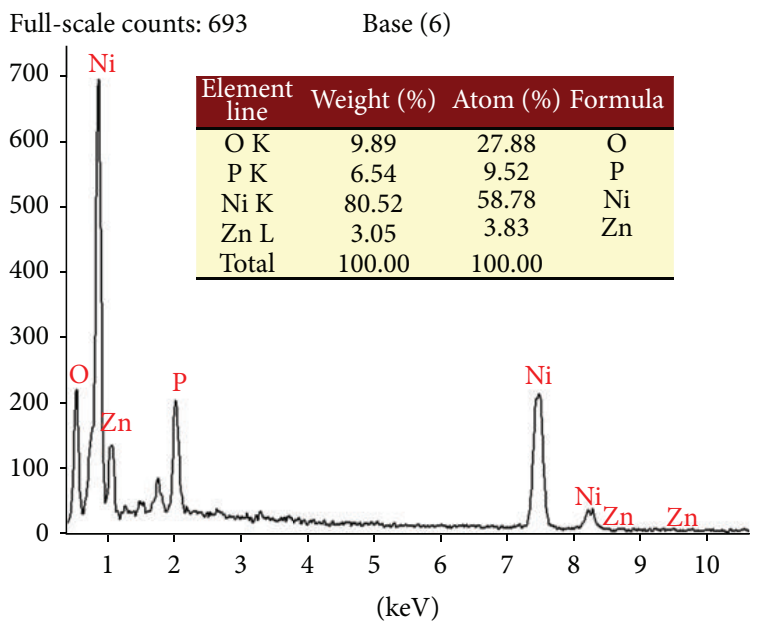

FIgURE 26: EDX diffractogram showing the \% of elements present on the EN-coated Mg sample with $2 \%$ nano-ZnO. of EN-coatings produced reduced the friction coefficient as shown in Figures 19 and 20.

\section{Conclusions}

A comprehensive experimental study under specific coating conditions on the influence of addition of various nanoadditivesss with SLS surfactant in the electroless nickel bath on the mechanical properties and tribological properties of the coatings produced has been carried out and the results are presented and analysed. In general, it has been observed that the surface finish, microhardness, specific wear rate and friction of the EN-coated layers improved significantly with the addition of nanoadditivesss. Based on the present investigations, the following specific conclusions could be drawn.

(i) There was an improvement in the surface finish (upto $67.86 \%, 72.3 \%, 29.63 \%$ in $R_{a}$ values) of the coatings due to addition of nanoadditivesss such as $\mathrm{Al}_{2} \mathrm{O}_{3}$, $\mathrm{SiO}$ and $\mathrm{ZnO}$ respectively to the $\mathrm{EN}$ bath. Addition of nanoadditivesss with surfactant concentration to the EN bath prevents the floatation of nickel particles generated during the chemical reaction of the coating process. Since the nickel particles do not float and move to the top surface of bath, more percentage of nickel particles get deposited as a fine layer thus improving the surface finish.

(ii) Addition of nanoadditivesss with SLS surfactant in the EN bath significantly improved the microhardness (upto $46.21 \%, 50.8 \%$ and $42.64 \%$ ) of the coatings due to addition of nanoadditivesss such as $\mathrm{Al}_{2} \mathrm{O}_{3}, \mathrm{SiO}$ and $\mathrm{ZnO}$, respectively.

(iii) The electroless $\mathrm{Ni}-\mathrm{P}$ coatings produced with the addition of nanoadditivesss with SLS surfactant in the EN bath improved the wear resistance (upto 65.38\% and $69.23 \%$ ) and lowered the friction coefficient (up to $52.38 \%$ and $61.90 \%$ ) when compared to the coatings produced without nanoadditivesss due to the increase in the hardness and the amorphous fraction in the coating. The smoother surface finish of EN-coatings produced reduced the friction coefficient.

\section{References}

[1] G. O. Mallory and J. B. Hajdu, Electroless Plating: Fundamentals and Applications, American Electroplaters and Surface Finishing Society, Orlando, Fla, USA, 1991.

[2] J. Sudagar, J. S. Lian, Q. Jiang, Z. H. Jiang, G. Y. Li, and R. Elansezhian, "The performance of surfactant on the surface characteristics of electroless nickel coating on magnesium alloy," Progress in Organic Coatings, vol. 74, pp. 788-793, 2012.

[3] W. Wolf, "Electroless plating," in Marks' Standard Handbook for Mechanical Engineers, E. A. Avallone and T. Baumeister, Eds., section 13.5, McGraw-Hill, 1996.

[4] B. Landkof, "Corrosion behaviour of AZ and ZA magnesium alloys in alkaline bath," in Proceedings of the International Conference on Magnesium Alloys and Their Applications, K. U. Kainer, Ed., p. 168, Wiley-VCH, Weinheim, Germany, 2000.

[5] K. Karuppusamy and R. Anantharam, "Pit-free nickel electroplating," Metal Finishing, vol. 90, no. 5, p. 15, 1992. 
[6] K. Hagiwara, J. Watanabe, and H. Honma, "Preparation of anisotropic conductive particles by electroless plating," Plating and Surface Finishing, vol. 84, no. 4, pp. 74-76, 1997.

[7] B. C. Tripathy, S. C. Das, G. T. Hefter, and P. Singh, "Zinc electrowinning from acidic sulfate solutions part I: effects of sodium lauryl sulfate," Journal of Applied Electrochemistry, vol. 27, no. 6, pp. 673-678, 1997.

[8] D. Wheeler, T. P. Moffat, G. B. McFadden, S. Coriell, and D. Josell, "Influence of a catalytic surfactant on roughness evolution during film growth," Journal of the Electrochemical Society, vol. 151, no. 8, pp. C538-C544, 2004.

[9] A. M. Alsari, K. C. Khulbe, and T. Matsuura, "The effect of sodium dodecyl sulfate solutions as gelation media on the formation of PES membranes," Journal of Membrane Science, vol. 188, no. 2, pp. 279-293, 2001.

[10] J. Medina-Valtierra, C. Frausto-Reyes, S. Calixto, P. Bosch, and V. Hugo Lara, "The influence of surfactants on the roughness of titania sol-gel films," Materials Characterization, vol. 58, no. 3, pp. 233-242, 2007.

[11] S. Manne and H. E. Gaub, "Molecular organization of surfactants at solid-liquid interfaces," Science, vol. 270, no. 5241, pp. 1480-1482, 1995.

[12] J. Sudagar, G. Bi, Z. Jiang, G. Li, Q. Jiang, and J. Lian, "Electrochemical polarization behaviour of electroless Ni-P deposits with different chromium-free pre-treatment on magnesium alloy," International Journal of Electrochemical Science, vol. 6, no. 7, pp. 2767-2788, 2011.

[13] R. Elansezhian, B. Ramamoorthy, and P. K. Nair, "The influence of SDS and CTAB surfactants on the surface morphology and surface topography of electroless Ni-P deposits," Journal of Materials Processing Technology, vol. 209, no. 1, pp. 233-240, 2009.

[14] P. Mukerjee and K. J. Mysels, NSRDS-NBS 36, US Government Printing Office, Washington, DC, USA, 1971.

[15] B. H. Chen, L. Hong, Y. Ma, and T. M. Ko, "Effects of surfactants in an electroless nickel-plating bath on the properties of $\mathrm{Ni}-\mathrm{P}$ alloy deposits," Industrial \& Engineering Chemistry Research, vol. 41, no. 11, pp. 2668-2678, 2002.

[16] Y.-C. Lin and J.-G. Duh, "Effect of surfactant on electrodeposited Ni-P layer as an under bump metallization," Journal of Alloys and Compounds, vol. 439, no. 1-2, pp. 74-80, 2007.

[17] N. M. Martyak, "Characterization of thin electroless nickel coatings," Chemistry of Materials, vol. 6, no. 10, pp. 1667-1674, 1994.

[18] B. N. Sahoo, B. Kandasubramanian, and A. Thomas, "Controlled anisotropic wetting behaviour of multi-scale slippery surface structure of non fluoro polymer composite," Journal of Polymers, vol. 2013, 2013.

[19] G. E. Aninwene II, D. Stout, Z. Yang, and T. J. Webster, "Nano$\mathrm{BaSO}_{4}$ : a novel antimicrobial additive to pellethane," International Journal of Nanomedicine, vol. 8, no. 1, pp. 1197-1205, 2013.

[20] H. F. Wang, S. M. Hao, Y. B. Bi, and R. H. Yu, "Effect of nanosized $\mathrm{Al}_{2} \mathrm{O}_{3}$ as additive on the sintering characteristics and vickers hardness of $\mathrm{Al}_{2} \mathrm{O}_{3} / \mathrm{Si}_{3} \mathrm{~N}_{4}$ compound ceramics," Advanced Materials Research, vol. 214, pp. 178-181, 2011.

[21] S. A. Pyachin, S. V. Nikolenko, A. A. Burkov, and N. A. Suy, "Electrospark coatings based on WC-Co alloys with aluminium oxide and carbon additives," Materials Sciences and Applications, vol. 4, pp. 186-190, 2013. 

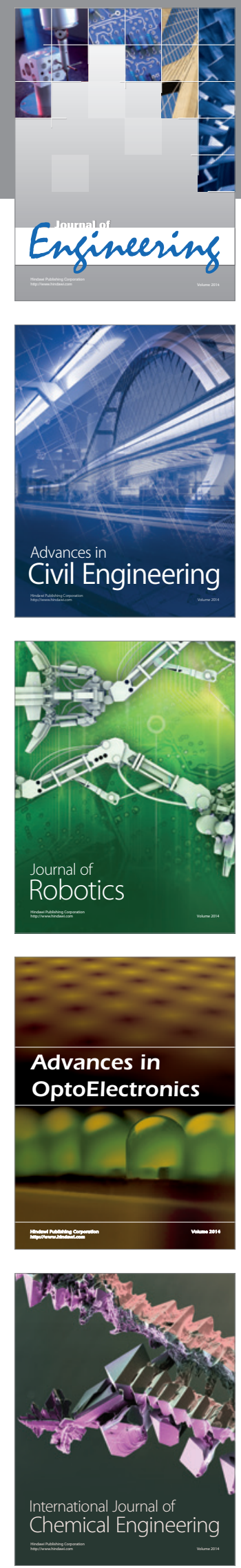

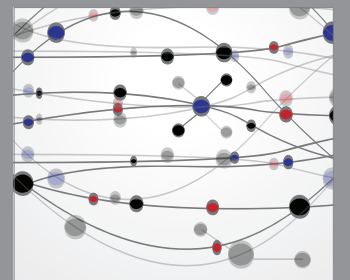

The Scientific World Journal
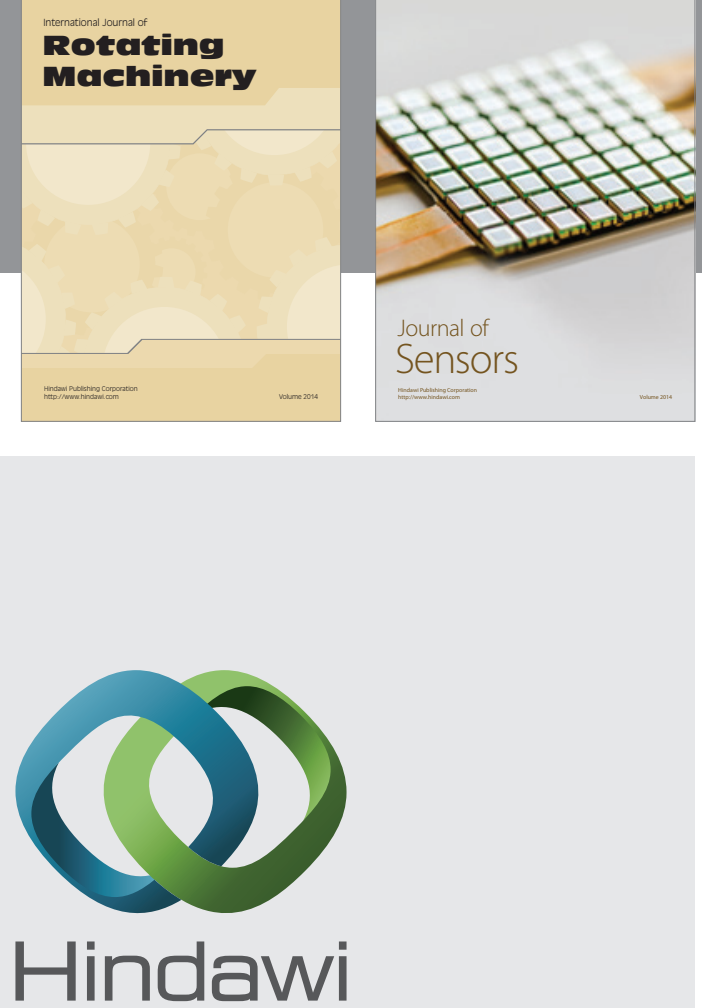

Submit your manuscripts at http://www.hindawi.com
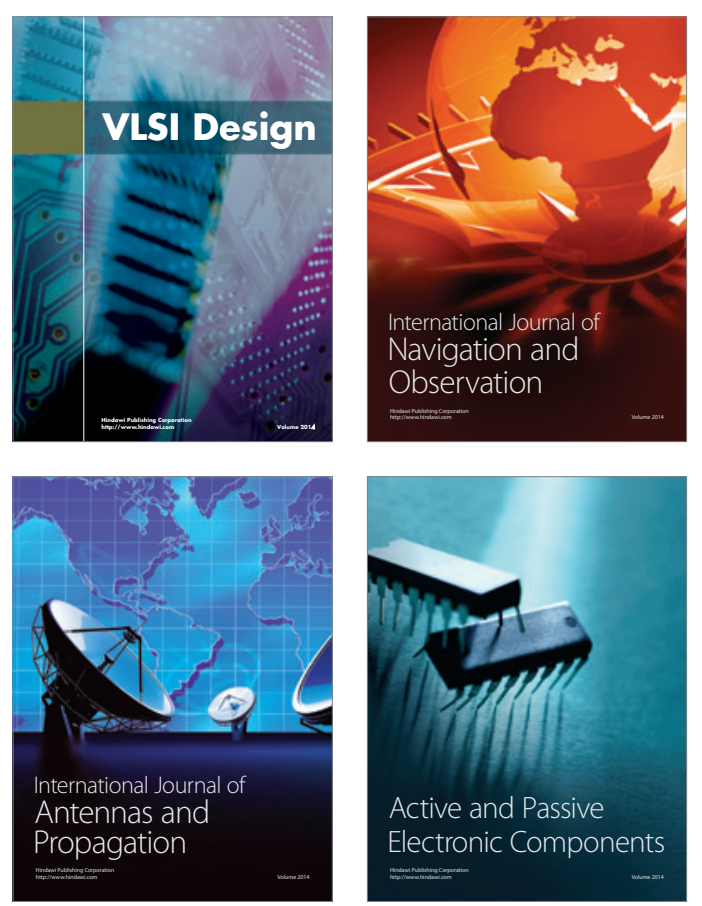
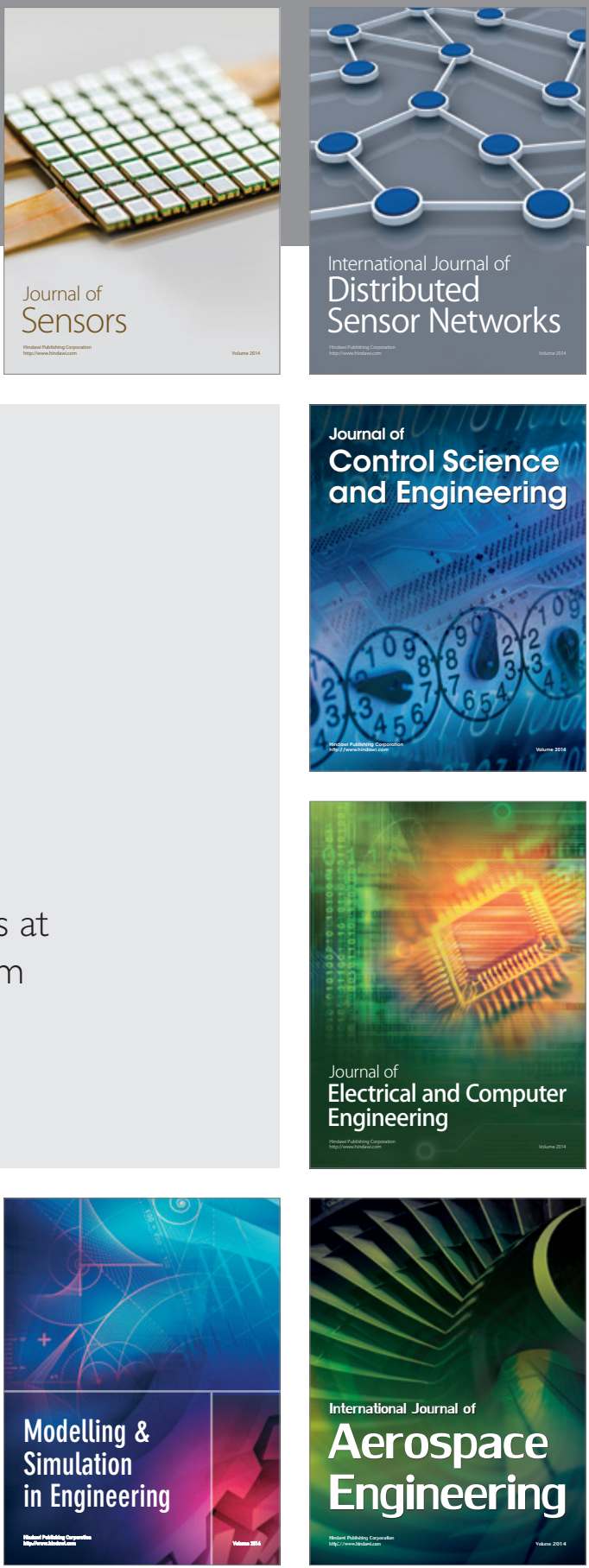

Journal of

Control Science

and Engineering
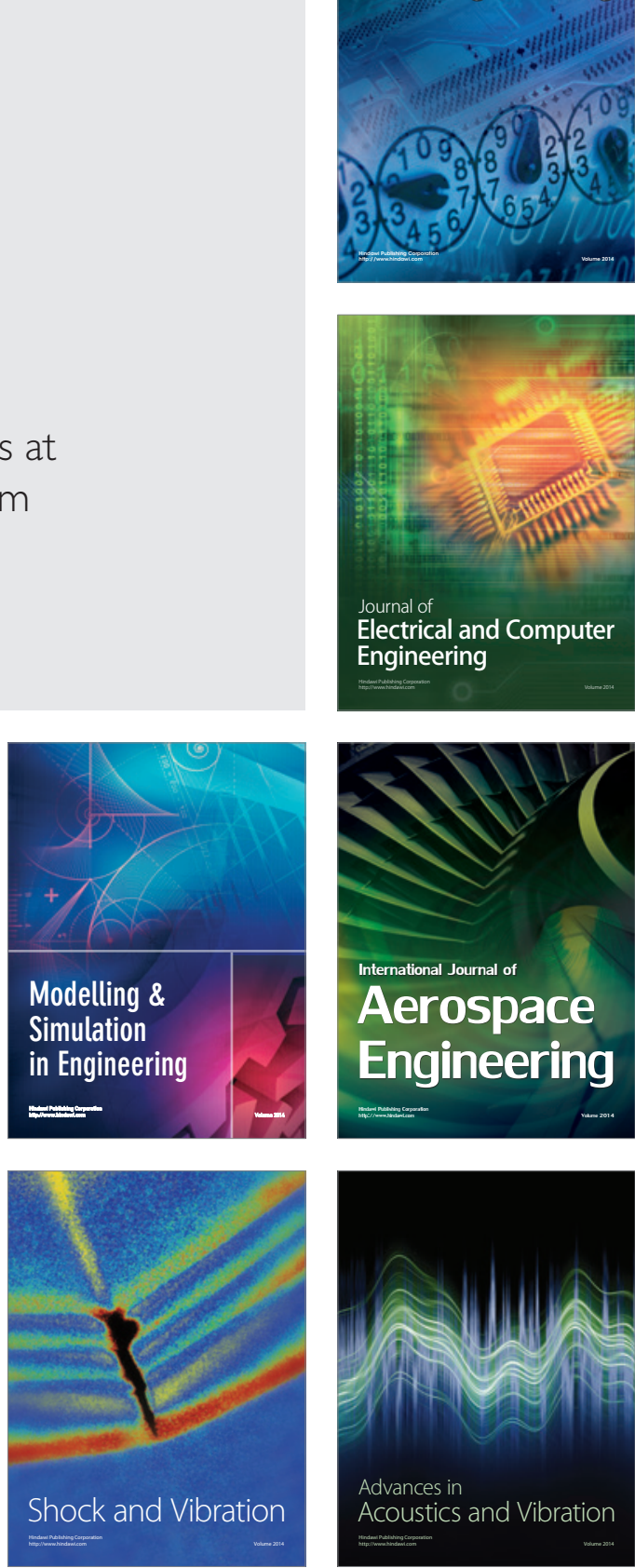